\title{
CONTRIBUIÇÕES PARA A PROPOSTA DE UMA POLÍTICA MUNICIPAL DE PAGAMENTO POR SERVIÇOS AMBIENTAIS: O CASO DE BOTUCATU/SP
}

\author{
Mariana Santos Leal ${ }^{1}$, Luiz César Ribas ${ }^{2}$ \\ ${ }^{1}$ Eng ${ }^{\mathrm{a}}$. Florestal, Especialista em Gerenciamento Ambiental, ESALQ/USP, São Paulo, SP, Brasil - mari_floresta @ hotmail.com \\ ${ }^{2}$ Eng. Florestal, Dr., Depto. de Economia, UNESP, Botucatu, SP, Brasil - lcribas@ fca.unesp.br \\ Recebido para publicação: 26/12/2012 - Aceito para publicação: 10/03/2014
}

\begin{abstract}
Resumo
Serviços Ambientais são os serviços prestados pelos ecossistemas que contribuem para a sustentação da vida e a manutenção do meio ambiente, e os Pagamentos por Serviços Ambientais (PSA) são mecanismos de remuneração aos prestadores de serviços ambientais por parte daqueles que se beneficiam dos mesmos. Botucatu é um município do estado de São Paulo com um grande potencial para implantação de PSA e sem atividades na área. Portanto, devido a essa demanda, por meio de um estudo comparativo de projetos de PSA, nas escalas federal e estadual, o presente trabalho tem como objetivo a análise, a seleção e a proposição de critérios, contribuindo assim com a criação de uma proposta de política de PSA para o município de Botucatu.
\end{abstract}

Palavras-chave: Recursos hídricos; projeto produtor de água; projeto mina d’água.

\begin{abstract}
Contributions to a municipal policy proposal for environmental services payment: the case of Botucatu/SP. Environmental services are the ones done by the nature, that supports both the life and the environment. Payments for Environmental Services (PES) are financial transfers by beneficiaries of environmental services for the ones who provide such services due to conservation practices. Botucatu is a city in São Paulo State with a great potential for PES. Therefore, this paper develops a comparative study of PES projects in Federal and State ranges, aiming to analyze, select and propose criteria in order to contribute to the creation of a PES policy for the city.

Keywords: Water resources; water producer project; headwater project.
\end{abstract}

\section{INTRODUÇÃO}

As atividades humanas estão cada vez mais dependentes dos recursos naturais devido ao processo de desenvolvimento das civilizações e crescimento populacional, que aumentaram a demanda por água, energia e alimentos (ZOLIN, 2010).

Serviços Ambientais podem ser considerados como os serviços prestados pelos ecossistemas que contribuem para a sustentação da vida e a manutenção do meio ambiente. De acordo com Silva (2010), os serviços mais comumente mencionados são os relacionados com o clima (sequestro de carbono e o controle da umidade, temperatura, precipitação e ventos), com o solo e hidrologia (manutenção da qualidade da água e do solo, controle de erosão e sedimentação, manutenção do habitat aquático) e com a biodiversidade (diversificação de culturas, corredores biológicos, serviços culturais e bioprospecção).

A maioria dos serviços e recursos naturais está degradada, devido à elevada taxa de exploração dos mesmos (GUEDES; SEEHUSEN, 2011) e à poluição da água e do solo causada pela lixiviação de fertilizantes e defensivos agrícolas e pela substituição de florestas por outros usos, que tendem a compactar o solo, diminuindo assim a infiltração da água e aumentando as enchentes e os processos erosivos, segundo a Agência Nacional de Águas (ANA) (2009).

Os ecossistemas são responsáveis por serviços importantes para a manutenção da quantidade e qualidade da água. Considerando que a escassez de água em quantidade e qualidade tende a aumentar, é 
importante que haja a incorporação da conservação das áreas com vegetação como estratégia de proteção de mananciais (WHATELY; HERCOWITZ, 2008).

Uma das consequências do descumprimento da legislação ambiental e da insuficiência de fiscalização é a perda de solo em bacias hidrográficas, processo esse responsável pela produção, transporte e deposição de sedimentos, contribuindo com o assoreamento (ZOLIN, 2010). Uma importante estratégia para a conservação dos recursos hídricos consiste em reduzir essa perda, pois uma das principais formas de poluição das águas é o escoamento superficial de terras agrícolas (SILVA, 2010).

Caso não sejam implantadas práticas conservacionistas capazes de mitigar os impactos, como poluição do solo e da água, compactação e/ou perda de solo, rapidamente ocorrerá o êxodo rural em consequência do abandono dessas áreas, ou a migração, com a abertura de novas áreas e sérios impactos ao meio ambiente (ANA, 2009).

Uma dessas práticas conservacionistas é a manutenção da mata ciliar, que contribui muito para a retenção dos agroquímicos e pode aumentar a infiltração da água, além de ser muito importante para a fauna e a flora.

Além de essas práticas melhorarem as condições ambientais, aliadas à boa gestão dos recursos hídricos, podem também contribuir economicamente ao diminuir gastos com tratamento de água e aumentar a qualidade de vida (WHATELY; HERCOWITZ, 2008). Um exemplo disso é o caso de Reis (2004), que, ao estudar o manancial de abastecimento do município de Piracicaba/SP, concluiu que os custos com tratamento da água aumentavam à medida que ocorria redução do percentual de cobertura vegetal na bacia.

A ideia da remuneração pelos serviços ambientais, como alternativa de política ambiental para mudança do quadro de degradação, decorre do reconhecimento de que os ecossistemas efetivamente prestam serviços importantes que devem ser conservados e que, enquanto não possuírem valor monetário, não farão parte da tomada de decisão (WHATELY; HERCOWITZ, 2008).

O Pagamento por Serviços Ambientais (PSA) pode promover a conservação do meio ambiente por meio de incentivos financeiros para os provedores de serviços ambientais, uma vez que, segundo a ANA (2009), PSA é uma transferência financeira de beneficiários e/ou usuários de serviços ambientais (princípio do "usuário-pagador") para os que proveem esses serviços, devido às práticas conservacionistas empregadas por eles (princípio do "provedor-recebedor"). Desse modo, o sistema de PSA, ao se basear nos princípios citados acima, reconhece o valor dos serviços ambientais e internaliza as externalidades negativas e positivas.

O PSA, ao apresentar uma utilidade transversal, auxilia, particularmente no caso brasileiro, a regularização de propriedades rurais, o processo de mapeamento do território, a aplicação do Código Florestal, a conservação dos solos e dos recursos florestais e hídricos e, em alguns casos, a implantação de medidas sanitárias em regiões de mananciais (VEIGA; GAVALDÃO, 2011).

Essa é uma política recente e inovadora, de instrumentos econômicos, que está atraindo muita atenção, já que se torna muito válida a junção das forças de mercado às políticas de comando e controle, a fim de se obterem melhores resultados relacionados aos serviços ambientais (ANA, 2009).

Os pagamentos, segundo Wunder et al. (2009), aparecem associados a uma ou mais das seguintes categorias de serviços ambientais: captura e retenção de carbono (captura de carbono por vegetação em crescimento ou retenção de carbono no solo e na vegetação), biodiversidade (regulação e estrutura do ecossistema, diversidade genética e de espécies), proteção dos recursos hídricos (purificação da água e regulação de fluxo) e beleza cênica (paisagens naturais e/ou culturais).

Para Wunder (2005), um determinado projeto, para ser classificado como PSA, tem que apresentar as seguintes características:

- deve ser uma transação voluntária;

- com um serviço ambiental bem definido (ou um tipo de uso da terra que assegure esse serviço);

- que é "comprado" por ao menos um comprador de serviços;

- de pelo menos um provedor de serviços;

- apenas se o provedor assegura a provisão do serviço prestado (condicionante).

Um erro grave e que pode comprometer a eficácia de um projeto de PSA é considerá-lo um substituto para políticas de redução de pobreza, uma vez que se trata de um instrumento de gestão 
ambiental (WUNDER et al., 2009), importante para resolução de conflitos, desenvolvimento econômico e ambiental sustentável e minimização de possíveis problemas futuros, como êxodo rural, escassez de água, gastos com tratamento de água e recuperação de solo e áreas de mananciais.

Um projeto de PSA apenas faz sentido se ele aumenta a provisão de um serviço ambiental em comparação com o cenário hipotético sem o PSA, a chamada adicionalidade (WUNDER et al., 2009).

A demanda por serviços também é fator fundamental e indispensável para o estabelecimento de um projeto de PSA. De acordo com Veiga e Gavaldão (2011), sua formação pode seguir diferentes rotas, como, por exemplo, a partir do interesse de comitês de bacias hidrográficas, em que a principal fonte de recursos provém da cobrança pelo uso da água ou da determinação de uma legislação, a qual cria condições para o estabelecimento dos esquemas de PSA. Mas também podem ser de origem voluntária, em que os beneficiários diretos dos serviços fazem pagamentos voluntários diretamente aos provedores, ou de grandes usuários de água, com intenção de mitigar ou compensar suas externalidades.

Também é importante lembrar que a implantação de um sistema de PSA tem um custo, sendo necessário então que seja feita anteriormente uma comparação entre os benefícios gerados e os custos de implantação, pois ele só é viável se os benefícios forem maiores que os custos.

$\mathrm{Na}$ maior parte das experiências, a quantia paga guarda pouca relação com a valoração monetária dos recursos naturais e dos serviços ambientais, sendo, na maioria das vezes, quantificada pelo custo de oportunidade da terra (WHATELY; HERCOWITZ, 2008), isto é, valores que correspondem ao lucro perdido por não converter florestas em outros tipos de uso do solo. Como a participação é voluntária, ela só se torna interessante se os valores pagos excederem os custos de oportunidade, resultando em aumento na renda do provedor. Assim, fica difícil a boa funcionalidade de PSA em casos que apresentam alto custo de oportunidade (WUNDER et al., 2009).

Segundo Veiga e Gavaldão (2011), ao analisarem iniciativas pioneiras de PSA de conservação dos recursos hídricos na Mata Atlântica, projetos de PSA também apresentam alguns gargalos e dificuldades, como:

- as de ordem econômica, devido a incertezas quanto à existência de recursos futuros e contínuos para a manutenção dos projetos de PSA e alto custo das atividades associadas e de transação;

- as de ordem técnica, como a baixa capacidade técnica na condução dos processos de gestão de projetos e ausência ou deficiência de processos de monitoramento;

- as de ordem institucional e legal, devido à inexistência de arcabouço legal e desconhecimento dos produtores em relação às suas obrigações ambientais.

O desenvolvimento de um sistema de PSA envolve diversos atores com diferentes interesses, o que torna complexo o processo de tomada de decisões, conforme dispõem diversos autores, como, por exemplo, Leal (2012).

A voluntariedade, fator que diferencia PSA da política de comando e controle, também tem que ser muito bem trabalhada, pois se somente alguns produtores isolados aderirem à mudança de comportamento, não havendo continuidade de projetos na paisagem, o resultado final do conjunto fica comprometido. Ressalte-se que o envolvimento da maioria não é um objetivo fácil de ser alcançado (LEAL, 2012).

De acordo com a ANA (2009), além do caráter econômico, os sistemas de PSA contribuem com a educação ambiental, na medida em que inserem uma nova relação entre fornecedores e beneficiários dos serviços e entre eles e a natureza.

Para que um projeto de PSA tenha êxito, seja efetivo e sustentável, é necessário trabalho dedicado e permanente para criar espaços de participação interinstitucionais, incorporando a sociedade civil, e para fortalecer instituições, estruturas, e organizações. É preciso trabalhar a sensibilização, comunicação e educação ambiental (SEHUSSEN; PREM, 2011).

Atualmente existem vários sistemas de PSA ao redor do mundo, principalmente em bacias hidrográficas, com alguns países da América Latina se destacando, tais como Costa Rica, El Salvador, Equador, Peru, Guatemala e Colômbia, além de Estados Unidos, Itália e Espanha (ZOLIN, 2010), sendo que a Costa Rica foi um dos primeiros países a implementar um esquema de PSA para conservação de florestas.

No Brasil, podemos encontrar projetos nas três fases seguintes (VEIGA; GAVALDÃO, 2011): 
1 - Implantação: a qual se refere a projetos em que os proprietários estejam engajados e com contratos assinados, atividades de conservação e restauração implantadas e baseadas no mapeamento do uso do solo e pagamentos realizados de acordo com o monitoramento das atividades designadas.

2 - Desenvolvimento: fase em que a avaliação socioeconômica, a seleção das áreas prioritárias, avaliação do uso da terra e análise econômica são realizadas, as rotas são definidas e os pagamentos são calculados de acordo com o financiamento garantido.

3 - Articulação: fase em que é criada a rede de atores interessados e capazes de implantar projetos de PSA.

Um exemplo de projeto brasileiro é o Produtor de Água, lançado pela ANA em escala federal, com a finalidade de compensar financeiramente os agentes que contribuem para a proteção e recuperação de mananciais estrategicamente importantes para abastecimento público.

Esse programa apresenta como objetivos a redução dos níveis de poluição difusa rural, principalmente os decorrentes dos processos de sedimentação e eutrofização em bacias hidrográficas estratégicas para o país, a difusão do conceito de manejo integrado do solo e da água e a garantia da sustentabilidade socioeconômica e ambiental dos manejos e práticas implantadas por meio de incentivos financeiros aos agentes selecionados (ANA, 2009).

Já no âmbito estadual, alguns estados como o Espírito Santo, que, por meio do programa Produtor de Água, sob a coordenação do Instituto Estadual do Meio Ambiente e Recursos Hídricos (IEMA), tem atuado em três microbacias e conta com recursos provenientes de 3\% da arrecadação dos royalties de petróleo (aproximadamente R\$15 milhões/ano) (VEIGA; GAVALDÃO, 2011).

Minas Gerais é outro estado que também tem trabalhado com projetos de PSA. O programa Bolsa Verde é financiado por $10 \%$ dos recursos do fundo de recuperação, proteção e desenvolvimento sustentável das bacias hidrográficas do estado de Minas Gerais (FHIDRO), dinheiro oriundo do setor elétrico (VEIGA; GAVALDÃO, 2011).

A Secretaria do Meio Ambiente do Estado de São Paulo, por seu turno, coordena um programapiloto de pagamento por serviços ambientais intitulado Mina d'Água. O projeto estadual paulista também tem, como objetivo, a proteção das nascentes em mananciais de abastecimento público, propondo-se a remunerar os produtores rurais que preservarem nascentes dentro de suas propriedades. As diretrizes para a execução do projeto Mina d'Água estão atualmente disciplinadas pela Resolução SMA nº 123/10.

$\mathrm{O}$ município de Extrema/MG, com base na Lei Municipal $\mathrm{n}^{\circ} 2.100 / 05$, regulamentada pelo Decreto $\mathrm{n}^{\circ} 1.703 / 06$, criou o projeto Conservador das Águas, que visa a implantação de ações para a melhoria da quantidade e qualidade das águas por intermédio do incentivo à adoção de práticas conservacionistas de solo, diminuindo a poluição decorrente dos processos erosivos, o aumento da cobertura vegetal e a implantação de saneamento ambiental nas propriedades rurais do município.

Na grande São Paulo, também estão presentes projetos ligados à conservação de mananciais de abastecimento público, como o Conservador das Águas do município de Extrema/MG, projeto em parceria com a ANA e The Nature Conservancy (TNC), e a iniciativa da Fundação O boticário de Proteção à Natureza, por meio do projeto Oásis, que prevê o pagamento para proprietários de terra que protegerem suas áreas na região da bacia de Guarapiranga, prioritariamente na porção inserida dentro do município de São Paulo (VEIGA; GAVALDÃO, 2011).

Outro programa que também está em andamento é o Produtor de Água nas bacias dos rios Piracicaba, Capivari, Jundiaí (PCJ), nos municípios de Joanópolis e Nazaré Paulista, também com o objetivo de incentivar a proteção dos mananciais por meio de remuneração financeira. Esse projeto se insere nas políticas estaduais e federal de cobrança pelo uso da água e de incentivos para a conservação das bacias hidrográficas (VEIGA; GAVALDÃO, 2011).

Embora o Brasil apresente experiências recentes, é um país promissor para implantação de programas de PSA, tanto públicos quanto privados, devido à demanda e à abundância de recursos e serviços ambientais, principalmente os hídricos, que, por serem um serviço mais tangível e a sociedade apresentar maior preocupação em relação à sua escassez, possuem maior número de projetos voltados a sua conservação, seguindo a mesma tendência mundial (GUEDES; SEEHUSEN, 2011).

A partir disso e considerando que o município de Botucatu apresenta áreas estrategicamente importantes a serem conservadas e nenhuma atividade relacionada a PSA, entende-se que a implantação de uma política de PSA no âmbito municipal é de grande valia para o desenvolvimento ambiental, não só do município em questão como também de toda a região do entorno. 
Por conseguinte, o presente trabalho tem como objetivo a análise, a seleção e a proposição de critérios, extraídos, principalmente, de duas políticas públicas de PSA, uma federal (programa Produtor de Água) e outra estadual de PSA (projeto Mina d'Água). Ele pode ser considerado um dos primeiros passos a serem tomados, contribuindo e norteando a criação de uma proposta de política de PSA para o município de Botucatu.

\section{MATERIAL E MÉTODOS}

\section{Área de estudo}

O município de Botucatu está localizado na região central do estado de São Paulo, a uma latitude de $22^{\circ} 52^{\prime} 20^{\prime \prime} \mathrm{S}$ e longitude de $48^{\circ} 26^{\prime} 37^{\prime} \mathrm{W}$. Apresenta uma área de $1.483 \mathrm{~km}^{2}$ e uma população de 127.328 habitantes (IBGE, 2007). A altitude média nas regiões mais altas é de 800 metros, enquanto que nas mais baixas é de 500 metros (FIGUEROA, 2008).

Fonte: Wikimedia, 2014.

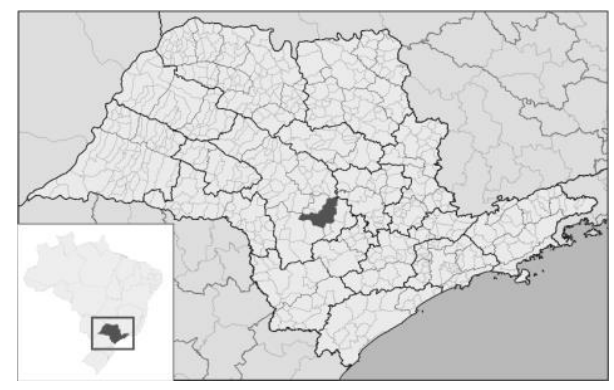

Figura 1. Localização do município de Botucatu no estado de São Paulo.

Figure 1. Location of Botucatu city in São Paulo State.

Botucatu está entre as bacias hidrográficas do médio Paranapanema e do Tietê/Sorocaba, sendo drenado pelas bacias do rio Tietê, ao norte, e do rio Pardo, afluente do Paranapanema, ao sul. Uma das microbacias mais importantes é a do rio Pardo, já que é nela que é feita a captação de água para o abastecimento público para os municípios de Botucatu e Pardinho. Como os melhores solos agrícolas estão nessa microbacia, o rio Pardo e seus afluentes são também utilizados para irrigação (FIGUEROA, 2008).

A cobertura vegetal nativa atual, que atinge apenas $10,45 \%$ da área total do município, está inserida nos biomas de Cerrado e Mata Atlântica (Floresta Estacional Semidecidual) e conta com Unidades de Conservação municipais, como o parque municipal natural Cachoeira da Marta e o parque municipal Cascata Véu de Noiva. Devido à riqueza vegetal, a região também abriga uma fauna diversa (FIGUEROA, 2008).

Botucatu apresenta uma formação geológica peculiar, devido à presença da Cuesta, uma elevação assimétrica, escarpada de um lado e com uma queda suave do outro. Embora apresente solos muito férteis importantes para a agricultura, como Latossolo e Nitossolo Vermelho (antigamente conhecidos por terra roxa), a declividade da Cuesta gera uma grande fragilidade quanto à erosão (ZIMBACK, 2008).

A depressão periférica, logo abaixo das escarpas da Cuesta, apresenta solo pobre em fertilidade para as culturas, por apresentarem quase que só areia em sua composição, e também por isso eles são bastante soltos e muito suscetíveis à erosão, sendo muito comum o aparecimento de voçorocas. No entanto, pelo fato de serem compostos por muita areia, eles apresentam uma facilidade de infiltração de água muito importante, devido à grande porosidade presente. A água percolada se desloca para as partes mais profundas da crosta terrestre (ZIMBACK, 2008).

Já nas imediações da cidade, principalmente sobre o alto da Cuesta, também são encontradas as chamadas áreas de recarga. Assim, o município está localizado sobre uma das "portas" do aquífero Guarani, o que faz com que sua responsabilidade diante da preservação seja redobrada.

Essas águas subterrâneas vão para um reservatório chamado aquífero Guarani, o maior manancial de água doce subterrânea transfronteiriço do mundo, que se estende pelo Brasil, Paraguai, 
Uruguai e Argentina (FIGUEROA, 2008). Ele se apresenta como uma importante reserva estratégica para o abastecimento da população e para o desenvolvimento das atividades econômicas e de lazer, com água de qualidade adequada ao consumo humano (ZIMBACK, 2008). As rochas apresentam alta porosidade e alto poder de absorção, portanto a água que escorre encharca essas rochas, ficando armazenada (FIGUEROA, 2008).

Parte do município de Botucatu está inserida em uma Área de Proteção Ambiental (APA), a “APA Corumbataí - Botucatu - Tejupá”, criada segundo o Decreto Estadual n ${ }^{\circ}$ 20.960/83, composta pelos três perímetros, com uma área total de 649.828 ha. O perímetro Botucatu possui 218.306 hectares e envolve nove municípios (SOS CUESTA, 2012).

O uso do solo em Botucatu, conforme informações do levantamento censitário das unidades de produção agropecuária do estado de São Paulo (SECRETARIA DE AGRICULTURA E ABASTECIMENTO, 2012), caracteriza-se da seguinte maneira: cerca de $30 \%$ de toda a área ocupada por reflorestamento e vegetação natural, enquanto a pastagem e as culturas perenes e temporárias ocupam por volta de $60 \%$ da área. Ainda de acordo com esse levantamento, o município apresenta maior número de pequenas e médias propriedades em relação ao de grandes propriedades.

Também devido à presença da Cuesta, a região apresenta uma paisagem exuberante, com muitos pontos turísticos, como cachoeiras, vales, trilhas e morros. $\mathrm{O}$ estímulo à preservação dessas áreas incentiva o aumento do ecoturismo, incrementando também a geração de renda do município, por meio de atividades consequentes.

\section{Metodologia}

No presente trabalho, foi empregado o estudo de caso e, à semelhança de Favaro (2012), realizou-se um estudo de caso representativo, típico e único.

O estudo de caso consiste em um método de pesquisa que utiliza, geralmente, dados qualitativos, coletados a partir de eventos reais, com o objetivo de explicar, explorar ou descrever fenômenos atuais inseridos em seu próprio contexto (YIN, 2009).

A partir de entrevistas realizadas nos órgãos ambientais e agrários do município, identificou-se a necessidade de implantação de uma política de PSA em Botucatu e, ao mesmo tempo, a falta de atividades nessa área. Em decorrência dessa necessidade, surgiu a ideia do presente trabalho: análise de projetos já em andamento para a posterior proposição de critérios a fim de contribuir com essa demanda.

Entre os vários projetos encontrados na literatura, foram selecionados dois para servirem de base, um de escala federal, o projeto Produtor de Água, devido a sua abrangência e importância de escala nacional, e outro estadual, no caso o projeto Mina d'Água, do estado de São Paulo, do qual o município faz parte.

Foi utilizado o método dedutivo (especulativo, geral para o específico), conforme Oliveira Neto (2007). A partir de uma observação global dos projetos de PSA, verificaram-se os principais aspectos sustentáveis que estão sendo contemplados pelos projetos estudados.

Os dados foram coletados de várias formas e diversos meios, como entrevistas locais, revisão bibliográfica e pesquisas na internet. Após a coleta das informações, desenvolveu-se o trabalho, que foi esquematizado em uma tabela para melhor visualização dos resultados.

\section{RESULTADOS E DISCUSSÃO}

A partir da análise e comparação entre os projetos Produtor de Água e Mina d’Água, de escala federal e estadual, respectivamente, foi realizada a seleção e a adaptação dos componentes para que melhor se enquadrassem na realidade de Botucatu.

A etapa seguinte foi então o desenvolvimento de uma proposta que tem como finalidade contribuir com a criação de uma política municipal de PSA adaptada às características do município em questão. Como pode ser observado na tabela abaixo, é possível depreender que os principais componentes básicos considerados em projetos de PSA são: contexto, objetivos, critérios para seleção de provedores de serviços ambientais, áreas prioritárias, intervenções, remuneração, valores a serem pagos e monitoramento.

Esses componentes foram analisados, tomados como base e adaptados às particularidades encontradas no município.

Os itens contexto e objetivo presentes na proposta foram basicamente os mesmos dos demais projetos, já que se trata de componentes mais genéricos. 
Tabela 1. Estudo comparativo entre casos de Pagamento por Serviços Ambientais nas escalas Federal, Estadual e Municipal.

Table 1. Comparative study of cases of Payment for Environmental Services in Federal, State and Municipal scales.

\begin{tabular}{|c|c|c|c|}
\hline Programa & $\begin{array}{c}\text { Produtor de Água } \\
\text { (Federal) }\end{array}$ & $\begin{array}{r}\text { Mina d'Água } \\
\text { (Estadual/SP) }\end{array}$ & $\begin{array}{c}\text { Proposta de PSA em Botucatu } \\
\text { (Municipal) }\end{array}$ \\
\hline Contexto & $\begin{array}{c}\text { - Compensação financeira aos } \\
\text { agentes que contribuam com a } \\
\text { proteção e recuperação de } \\
\text { mananciais. }\end{array}$ & $\begin{array}{l}\text { - Remuneração dos } \\
\text { produtores rurais. } \\
\text { - Preservação de nascentes } \\
\text { de propriedades rurais. } \\
\text { - Conciliação entre } \\
\text { preservação ambiental e } \\
\text { geração de renda. }\end{array}$ & $\begin{array}{c}\text { - Remuneração dos produtores } \\
\text { rurais. } \\
\text { - Conciliação entre preservação e } \\
\text { recuperação das nascentes, } \\
\text { mananciais e vegetação nativa e } \\
\text { geração de renda. }\end{array}$ \\
\hline Objetivos & $\begin{array}{l}\text { - Incentivos financeiros aos agentes } \\
\text { selecionados. } \\
\text { - Redução dos níveis de poluição } \\
\text { difusa rural. } \\
\text { - Mitigação dos processos de } \\
\text { sedimentação e eutrofização de } \\
\text { bacias hidrográficas estratégicas. } \\
\text {-Difusão do manejo integrado do } \\
\text { solo e da água. }\end{array}$ & $\begin{array}{l}\text { - Proteção das nascentes em } \\
\text { mananciais de } \\
\text { abastecimento público. }\end{array}$ & $\begin{array}{c}\text { - Proteção das nascentes e dos } \\
\text { mananciais. } \\
\text { - Conservação de Matas Ciliares e } \\
\text { remanescentes florestais. } \\
\text { - Uso de técnicas adequadas de } \\
\text { conservação do solo e de práticas } \\
\text { agroecológicas. } \\
\text { - Prevenção de processos de } \\
\text { erosão e poluição hídrica. } \\
\text { - Promoção da beleza cênica. }\end{array}$ \\
\hline $\begin{array}{l}\text { Critérios para } \\
\text { seleção de } \\
\text { provedores de } \\
\text { serviços } \\
\text { ambientais }\end{array}$ & $\begin{array}{c}\text { - Produtores rurais com projeto } \\
\text { indicando a situação atual e as } \\
\text { medidas de conservação de água e } \\
\text { solo pretendidas para abatimento de } \\
\text { erosão, outorga da água, caso seja } \\
\text { usuário de recursos hídricos, e } \\
\text { certificado de regularidade referente } \\
\text { à cobrança se o for usuário de } \\
\text { recursos hídricos sujeitos à } \\
\text { cobrança. }\end{array}$ & $\begin{array}{l}\text { - Produtores rurais das } \\
\text { áreas prioritárias, dando-se } \\
\text { preferência a agricultores } \\
\text { familiares, com } \\
\text { participação limitada a } \\
\text { quatro nascentes por } \\
\text { produtor. }\end{array}$ & $\begin{array}{l}\text { - Proprietários rurais, } \\
\text { prioritariamente agricultores } \\
\text { familiares alocados nas áreas } \\
\text { prioritárias, que já apresentem } \\
\text { atividades de recuperação e } \\
\text { conservação de vegetação nativa } \\
\text { e de solo, uso de práticas } \\
\text { agroecológicas ou que } \\
\text { apresentem interesse em } \\
\text { implantá-las. Também devem } \\
\text { estar com toda a documentação } \\
\text { da propriedade em dia. }\end{array}$ \\
\hline $\begin{array}{l}\text { Áreas } \\
\text { prioritárias }\end{array}$ & $\begin{array}{c}\text { - Cabe ao Comitê da Bacia } \\
\text { identificar e hierarquizar as suas } \\
\text { sub-bacias prioritárias. }\end{array}$ & $\begin{array}{c}\text { - Cabe às prefeituras } \\
\text { municipais a seleção de } \\
\text { áreas prioritárias de acordo } \\
\text { com as características do } \\
\text { município. }\end{array}$ & $\begin{array}{l}\text { - Remanescentes conservados de } \\
\text { vegetação nativa; áreas de recarga } \\
\text { do Aquífero Guarani, da Cuesta e } \\
\text { da APA; microbacia do Rio Pardo } \\
\text { e áreas com o uso predominante } \\
\text { de práticas agroecológicas. }\end{array}$ \\
\hline Intervenções & $\begin{array}{c}\text { - Serviços de conservação do solo, } \\
\text { implantação de florestas novas e } \\
\text { preservação de remanescentes } \\
\text { florestais. }\end{array}$ & $\begin{array}{l}\text { - Medidas e ações com o } \\
\text { objetivo de manter a área } \\
\text { livre de fatores de } \\
\text { degradação (fogo, presença } \\
\text { de animais, focos de } \\
\text { erosão), que favoreçam a } \\
\text { regeneração natural da } \\
\text { vegetação e plantio de } \\
\text { mudas de espécies nativas } \\
\text { de ocorrência regional. }\end{array}$ & $\begin{array}{l}\text { - Preservação das áreas com } \\
\text { vegetação remanescente, } \\
\text { implantação de vegetação nativa } \\
\text { em APP, atividades de } \\
\text { conservação do solo, retirada dos } \\
\text { fatores de degradação dessas } \\
\text { áreas e implantação ou melhoria } \\
\text { de técnicas agroecológicas. }\end{array}$ \\
\hline Remuneração & $\begin{array}{c}\text { - Remuneração por florestas já } \\
\text { existentes: quanto maior o } \\
\text { percentual de APP a recuperar, } \\
\text { maior é o valor a ser pago por } \\
\text { hectare (ha) de floresta existente. } \\
\text { - Propriedades que não apresentam } \\
\text { déficits em APPs, o pagamento se } \\
\text { dará por hectare de floresta e } \\
\text { dependendo do nível de conservação } \\
\text { das mesmas. Os custos das práticas } \\
\text { implantadas serão cobertos total ou } \\
\text { parcialmente, dependendo do } \\
\text { abatimento da poluição difusa. }\end{array}$ & $\begin{array}{l}\text { - A remuneração é referente } \\
\text { ao estado em que a } \\
\text { nascente se encontra, de } \\
\text { acordo com o estágio de } \\
\text { conservação da vegetação } \\
\text { (APP), com o uso, vazão e } \\
\text { localização da mesma. }\end{array}$ & $\begin{array}{l}\text { - Remuneração de acordo com a } \\
\text { área e o estágio sucessional das } \\
\text { áreas com vegetação nativa } \\
\text { remanescente, que podem ser } \\
\text { corredores ecológicos, APP, RPPN } \\
\text { e Reserva Legal, entre outras; da } \\
\text { implantação de novas áreas (como } \\
\text { cercas, mudas, adubos), também } \\
\text { de acordo com a área a ser } \\
\text { recuperada, e do uso e implantação } \\
\text { de técnicas de agroecologia, } \\
\text { considerando diferentes valores } \\
\text { para cada tipo de atividade. }\end{array}$ \\
\hline
\end{tabular}




\begin{tabular}{|c|c|c|c|}
\hline $\begin{array}{l}\text { Valores a } \\
\text { serem pagos }\end{array}$ & $\begin{array}{l}\text { - Os valores são estabelecidos por } \\
\text { cada bacia hidrográfica conforme } \\
\text { suas características e os pagamentos } \\
\text { são proporcionais aos benefícios } \\
\text { ambientais gerados, sendo que cada } \\
\text { prática apresenta um método } \\
\text { diferente de cálculo. }\end{array}$ & $\begin{array}{c}\text { - Custo de oportunidade } \\
\text { regional } \\
\text { Valor=V Ref x (F Prot + F } \\
\text { Imp) x } 0,2 \\
\text { V Ref: Valor de referência } \\
\text { (relacionado ao custo de } \\
\text { oportunidade) } \\
\text { F Prot: Fator de proteção da } \\
\text { nascente } \\
\text { F Imp: Fator de } \\
\text { importância da nascente }\end{array}$ & $\begin{array}{c}\text { - Valores relacionados ao custo } \\
\text { de oportunidade da terra e/ou } \\
\text { custo de execução das } \\
\text { intervenções. }\end{array}$ \\
\hline Monitoramento & $\begin{array}{l}\text { - Indicadores da diminuição da } \\
\text { erosão: vazão e a turbidez da água } \\
\text { em períodos preestabelecidos, } \\
\text { verificados pelo contratante. }\end{array}$ & $\begin{array}{c}\text { - O sistema de } \\
\text { monitoramento do } \\
\text { programa ficará a cargo de } \\
\text { cada município. }\end{array}$ & $\begin{array}{l}\text { - Monitoramento a curto prazo: } \\
\text { análise da qualidade e } \\
\text { quantidade (vazão) da água. } \\
\text { Longo prazo: levantamento da } \\
\text { fauna e flora das áreas com } \\
\text { vegetação nativa. }\end{array}$ \\
\hline
\end{tabular}

Como Botucatu apresenta uma área bastante significativa, onde se faz o uso de práticas agroecológicas, região conhecida como Demétria, esse método de cultivo agrícola foi adicionado aos critérios de seleção de provedores, já que consiste em importante artifício para a conservação do meio ambiente. Com a ampliação do uso dessas práticas, tanto a área de produção quanto o mercado dos produtos orgânicos podem se expandir, fortalecendo eventos como a feira de produtos orgânicos, em que os produtores vendem direto ao consumidor (FIGUEROA, 2008).

A questão das áreas prioritárias foi um dos componentes com maior relevância na construção da proposta, já que o município se localiza em uma região extremamente delicada, que consiste da Cuesta e das áreas de recargas do aquífero Guarani, sendo imprescindível a conservação das mesmas.

Como uma proposta municipal se mostra mais específica às características locais, a microbacia do rio Pardo também foi escolhida como prioritária, devido à captação de água para irrigação e abastecimento público para os municípios de Botucatu e Pardinho, diferentemente dos outros projetos que deixam esse item em aberto. Segundo Conte e Leopoldo (2001), como o rio Pardo trata-se de um manancial estrategicamente importante para a região, é necessário que providências conservacionistas sejam tomadas para que se possa alcançar o estado ecológico adequado aos seus usos preponderantes e evitar piores preocupações futuras. Ao se investir na melhoria da conservação da vegetação e do solo das bacias, principalmente esta, utilizada para captação de água, acaba-se economizando recursos financeiros no tratamento da água antes de ser distribuída à população.

Uma atitude que se procurou estimular foi a criação de novas áreas de Reserva Particular do Patrimônio Natural (RPPN), ao incluí-las nas áreas a serem remuneradas, de modo que a vegetação natural e todos os seus benefícios também aumentariam.

O quesito valores a serem pagos também consistiu em valores relacionados ao custo de oportunidade da terra e de execução das intervenções, como vem sendo aplicado na grande maioria dos projetos, sendo que os pagamentos são condicionados ao cumprimento das obrigações previstas em contrato, firmado entre o provedor de serviços ambientais e a Prefeitura/Secretaria Municipal de Meio Ambiente.

Os recursos podem ser provenientes de diversas fontes, como companhia de saneamento básico, comitê de bacias hidrográficas, medidas de compensação por atividades de significativo impacto ambiental e indenizações ambientais.

Em suma, os componentes da proposta de PSA para o município de Botucatu tenderam a ser mais específicos, pois quanto menor a escala do projeto, maior tendência à especificidade.

\section{CONCLUSÃO}

- Todo o material considerado apresentou ótimos subsídios, de modo que o presente trabalho conseguiu alcançar o objetivo proposto, o qual consistia em analisar uma política federal de PSA (programa Produtor de Água) e uma política estadual de PSA (projeto Mina d'Água) para que, em seguida, fosse possível selecionar e propor componentes adequados à realidade do município, contribuindo assim para a criação de uma política municipal de PSA em Botucatu. 


\section{REFERÊNCIAS}

AGÊNCIA NACIONAL DE ÁGUAS (ANA). Programa Produtor de Água: Manual operativo. Brasília: ANA, 2009. 67 p.

BRASIL. Lei Federal $n^{0}$ 10.831, de 23 de dezembro de 2003. Dispõe sobre a agricultura orgânica e dá outras providências. Diário Oficial da União, Brasília, DF, 23 dez. 2003. Disponível em: <http://www.planalto.gov.br/ccivil_03/leis/2003/L10.831.htm>. Acesso em: 30/05/2012.

CONTE, M. L.; LEOPOLDO, P. R. Avaliação de recursos hídricos: Rio Pardo, um exemplo. São Paulo: Editora UNESP, 2001. 141 p.

EXTREMA. Lei ${ }^{\circ} 2.100$, de 21 de dezembro de 2005. Cria o Projeto Conservador das Águas, autoriza o executivo a prestar apoio financeiro aos proprietários rurais e dá outras providências. Extrema, MG, 21 dez. 2005. Disponível em: 〈http://www.comitepcj.sp.gov.br/download/Lei-2100-05_Extrema-MG.pdf〉. Acesso em: 26/01/2012.

EXTREMA. Decreto $n^{\circ} 1.703$, de 06 de abril de 2006. Regulamenta a Lei ${ }^{\circ} 2.100 / 05$ que cria o projeto conservador das águas, autoriza o executivo a prestar apoio financeiro aos proprietários rurais e dá outras providências. Extrema, MG, 06 abril 2006. Disponível em: <http://www.comitepcj.sp.gov.br/download/ Decreto-1703-06_Extrema-MG.pdf $>$. Acesso em: 26/01/2012.

FAVARO, A. K. M do I. Pagamentos por Serviços Ambientais: uma contribuição para a saúde ambiental no contexto das mudanças climáticas - Estudo de Caso: Rio Grande da Serra (SP). 234 p. Dissertação. (Mestrado da Faculdade de Saúde Pública) - Universidade de São Paulo, São Paulo, 2012.

FIGUEROA, J. C. Botucatu: cidade dos bons ares e das boas escolas. São Paulo: Noovha América, 2007. $200 \mathrm{p}$.

GUEDES, F. B.; SEEHUSEN, S. E. O PSA na Mata Atlântica - situação atual, desafios e recomendações. In: GUEDES, F. B.; SEEHUSEN, S. E. (organizadoras.) Pagamento por Serviços Ambientais na Mata Atlântica - Lições aprendidas e desafios. Brasília: MMA, 2011. p. 225 - 249.

INSTITUTO BRASILEIRO DE GEOGRAFIA E ESTATÍSTICA (IBGE). Disponível em: <http://www.ibge.gov.br/cidadesat/painel/painel.php?codmun=350750>, 2007. Acesso em: 07/05/2012.

LEAL, M. S. Contribuições para a propositura de uma Política Municipal de Pagamento por Serviços Ambientais: o caso de Botucatu/SP. 64 f. Monografia (Curso de Especialização em Gerenciamento Ambiental) - Escola Superior de Agricultura "Luiz de Queiroz" - Universidade de São Paulo, Piracicaba, 2012.

OLIVEIRA NETO, O. de. Manual de Monografia Jurídica. São Paulo: Editora Quartier Latin do Brasil, 2007. 197 p.

REIS, L. V. S. Cobertura florestal e custo do tratamento de águas em bacias hidrográficas de abastecimento público: caso do manancial do município de Piracicaba. $215 \mathrm{f}$. Tese (Doutorado em Recursos Florestais) - Escola Superior de Agricultura "Luiz de Queiroz", Universidade de São Paulo, Piracicaba, 2004.

SÃO PAULO. Decreto estadual no 20.960, de 8 de junho de 1983. Declara área de proteção ambiental as regiões situadas em diversos municípios, dentre os quais Corumbataí, Botucatu e Tejupá. Diário Oficial do Estado, São Paulo, SP, 09 jun 1983. Disponível em: <http://www.ambiente.sp.gov.br/wpcontent/uploads/decreto/1983/1983-Dec-20960.pdf>. Acesso em: 10/05/2012.

SÃO PAULO. Resolução SMA n ${ }^{0}$ 123, de 24 de dezembro de 2010. Define as diretrizes para a execução do Projeto Mina D'água - Projeto de Pagamento por Serviços Ambientais, na modalidade proteção de nascentes, no âmbito do Programa de Remanescentes Florestais, e revoga a Resolução SMA n ${ }^{\circ}$ 61, de 24 de junho de 2010. Diário Oficial do Estado, São Paulo, SP, 25 dez. 2010, seção I, p. 24 - 25. Disponível em: 〈http://www.ambiente.sp.gov.br/legislacao/estadual/resolucoes/2010_res_est_sma_123.pdf >. Acesso em: 10/05/2012. 
SECRETARIA DE AGRICULTURA E ABASTECIMENTO. Levantamento Censitário das Unidades de Produção Agrícola do Estado de São Paulo. Disponível em: <http://www.cati.sp.gov.br/projetolupa/ sobreolupa.php>. Acesso em: 09/05/2012.

SEEHUSEN, S. E.; PREM, I. Por que Pagamentos por Serviços Ambientais? In: GUEDES, F. B.; SEEHUSEN, S. E. (organizadoras). Pagamento por Serviços Ambientais na Mata Atlântica - Lições aprendidas e desafios. Brasília: MMA, 2011. p. 15 - 53.

SILVA, B. R. Pagamento por Serviços Ambientais e a Proteção e Conservação dos Recursos Hídricos da Sub-Bacia do Alto Tietê - Cabeceiras. 65 f. Monografia (Especialização em Gerenciamento Ambiental) - Escola Superior de Agricultura Luiz de Queiroz, Universidade de São Paulo, Piracicaba, 2010.

SOS CUESTA. ONG SOS Cuesta de Botucatu. Disponível em: <http://www.soscuesta.org.br/apa botucatu.htm>. Acesso em: 19/05/2012.

VEIGA, F.; GAVALDÃO, M. Iniciativas de PSA de Conservação dos Recursos Hídricos na Mata Atlântica. In: GUEDES, F. B.; SEEHUSEN, S. E. (organizadoras). Pagamento por Serviços Ambientais na Mata Atlântica - Lições aprendidas e desafios. Brasília: MMA, 2011. p. 123 - 182.

WHATELY, M.; HERCOWITZ, M. Serviços ambientais: conhecer, valorizar e cuidar: subsídios para a proteção dos mananciais de São Paulo. São Paulo: Instituto Socioambiental, 2008. 119 p.

WIKIMEDIA. Disponível em: <http://upload.wikimedia.org/wikipedia/commons/2/29/SaoPaulo_Municip_ Botucatu.svg>. Acesso em: 29/01/2014.

WUNDER, S. Payments for environmental services: some nuts and bolts. CIFOR Ocasional Paper, n. 42, 24 p., 2005.

WUNDER, S.; BÖRNER, J.; TITO, M. R.; PEREIRA, L. Pagamentos por Serviços Ambientais: perspectivas para a Amazônia Legal. Brasília: MMA, 2009. 144 p.

YIN, R. K. Case study research, design and methods (applied social research methods). Thousand Oaks. California: Sage Publications, 312 p., 2009.

ZIMBACK, C. R. L. A Geologia do Município de Botucatu. In: Lavapés, Água e Vida: nos caminhos da Educação Ambiental. Botucatu, SP: Gráfica Editora Lar Anália Franco, 2008. 216 p.

ZOLIN, C. A. Análise e otimização de projetos de Pagamentos por Serviços Ambientais (PSA) utilizando Sistemas de Informações Geográficas (SIG) - o caso do município de Extrema, MG. 128 f. Tese (Doutorado em Irrigação e Drenagem) - Escola Superior de Agricultura Luiz de Queiroz, Universidade de São Paulo, Piracicaba, 2010. 